\title{
Hound Breed
}

National Cancer Institute

\section{Source}

National Cancer Institute. Hound Breed. NCI Thesaurus. Code C53702.

Most hounds share the common ancestral trait of being used for hunting. Some use acute scenting powers to follow a trail. Others demonstrate phenomenal stamina as they relentlessly run down quarry. The Hound Group encompasses a diverse lot. There are Pharaoh Hounds, Norwegian Elkhounds, Afghans and Beagles, among others. Some hounds share the distinct ability to produce a unique sound known as baying. 